\title{
Performance assessment of six public health programs in Katsina State, Nigeria
}

\author{
Laurent Cleenewerck $^{1}$, Devender Bhalla ${ }^{2}$, Kabiru Abubakar Gulma ${ }^{3}$ \\ ${ }^{1}$ Pôle Universitaire EUCLIDE / Euclid University, USA \\ ${ }^{2}$ Sudan League of Epilepsy and Neurology ${ }^{\circledR}$, Sudan \\ ${ }^{3}$ Pôle Universitaire EUCLIDE / Euclid University, Bangui
}

\section{Article Info \\ Article history: \\ Received Feb 12, 2019 \\ Revised Feb 22, 2019 \\ Accepted Feb 28, 2019}

\section{Keywords:}

Africa

Health systems

Pharmaceutical

Programs

Public health

\begin{abstract}
This research aimed to evaluate the performance of six ongoing public health programs through core performance indicators in Katsina State, Nigeria. The healthcare delivery in Africa is mostly program-based. This requires that such programs need to be evaluated which may in turn help to identify any existing gaps towards the improvement of patients' access and coverage to their given service. We identified all active health facilities where our programs on malaria, Routine Immunization (RI), Family Planning (FP), Tuberculosis and Leprosy (TBL), HIV/AIDS, and Free Medicare (FMC) were being carried out. After that, a representative sample was derived to obtain data regarding five key performance indicators by using a Logistics Indicators Assessment Tool. Of 1,718 facilities, a total of 983 (57.22\%) were visited, In other words, by assuming a normal distribution; each facility expectedly covers only 3,371 individuals. All programs provided different and diverse results on each indicator; however, the most obvious challenge was in the stock-out and demand vs. receipt of required medications. These are particularly for malaria, FMC, FP, and HIV. For instance, the stock-out lasted 222 days for malaria and 135 days for FP. Despite this, none of the programs had a lower than gold-standard near-term availability of required products. Program-based healthcare delivery is inadequate and ineffective unless the local system gets simultaneously developed. If required medications are not becoming available, optimal access, coverage, and benefits cannot be expected to be obtained. Clearly, Nigeria experiences a push system of meeting term supplies. Nigeria needs to strengthen its pharmaceutical system.
\end{abstract}

Copyright () 2019 Institute of Advanced Engineering and Science. All rights reserved.

\section{Corresponding Author:}

Kabiru Abubakar Gulma,

School of Global Health and Bioethics,

Pôle Universitaire EUCLIDE / Euclid University, Bangui, Central African Republic.

Email: kabiru.mcgulma@gmail.com

\section{INTRODUCTION}

Like elsewhere, Africa's public health is multi-dimensional, multi-actor driven, fragmented, and fragile, where everything is likely to be affected by everything else [1]. For instance, in Africa, a single sudden change in policy has the capacity to hamper patient's access to treatment immediately and to in turn devoid them of possible benefits in terms of favorable patient-level outcome and overall reduction of disease burden in the country [2]. Here, in Africa, the majority of healthcare delivery is "vertical" and program-based. Thus, outcomes are dependent on both in-countries as well as external factors [3]. Thus, there is a need to systematically examine such public health programs that may help identify opportunities, gaps, and challenges that might hamper patient's access and coverage to any given treatment. However, little has been formally done before on this. Assessment of programs is also crucial because 
elsewhere it is shown that despite enormous program-based fund investment in Africa, little improvement in the strengthening of the local healthcare system has been achieved [3]. Thus, continuing with our vision of establishing a reliable public health profile and positive international presence of scientifically silent locations, and with an objective to systematically assess several ongoing public health programs, we performed this work in Katsina (Nigeria). This, if validated, would provide evidence-based conclusions on how the programs are functioning in an African cultural context before we may propose improvements, for the local and global level. Table 1 gives details of the six (6) supply chain systems being investigated [4-10].

Table 1. Supply chain systems in Katsina State, Nigeria

\begin{tabular}{clcc}
\multicolumn{4}{c}{ Table 1. Supply chain systems in Katsina State, Nigeria } \\
\hline S/N & \multicolumn{1}{c}{ Supply Chain System } & $\begin{array}{c}\text { Number of Health Facilities } \\
\text { Where Services Are Provided }\end{array}$ & $\begin{array}{c}\text { Number of Local } \\
\text { Governments Covered }\end{array}$ \\
\hline 1 & Malaria & 1.178 of $1.718(100 \%)$ & 34 of $34(100 \%)$ \\
2 & Family Planning & 393 of $1.718(23 \%)$ & 34 of $34(100 \%)$ \\
3 & Routine Immunization & 1.623 of $1.718(94 \%)$ & 34 of $34(100 \%)$ \\
4 & Tuberculosis and Leprosy Control & 173 of $1.718(10 \%)$ & 34 of $34(100 \%)$ \\
5 & $*$ HIV/AIDS & 19 of $1.718(1.1 \%)$ & 16 of $34(47 \%)$ \\
6 & Free Medicare & 25 of $1.718(1.5 \%)$ & 16 of $34(47 \%)$ \\
\hline *HIV/AIDS: Human Immunodeficiency Virus/Acquired Immune Deficiency Syndrome; S/N: Serial \\
Number
\end{tabular}

\section{RESEARCH METHOD}

\subsection{The significance of disease conditions addressed}

The public health programs that we included were malaria, HIV/AIDS, maternal and child health, family planning, routine immunization, tuberculosis, and leprosy. These cover disease conditions of preventative, social, and communicable interest; all of which are of particular importance in our country's context [3]. Moreover, these conditions have a cross-therapeutic implication as well. For instance, those with cerebral malaria are five times more likely to develop epilepsy and dementia, just like tuberculosis, leprosy, and childhood infections for various neurological and mental health conditions. Mainly speaking, maternal and child health risk factors may account for $40.0 \%$ of epilepsy cases [11-13].

\subsection{The significance of addressing nigeria}

Nigeria is a large, diverse, and most populous country of Africa. It has about 182 million individuals who belong to at least 250 ethnic groups and speaks 350 languages. The population is predominantly youth probably because the current life expectancy is merely 55 years. Here, malaria causes $25.0 \%$ under-5 year deaths, and its caseload may change drastically over a short period time [3]. The HIV burden is second highest from among all countries. The incidence of TB is 311/100,000, one of the highest in the World. The system-related gaps are also visibly present, for instance, the general workforce for healthcare delivery is grossly inadequate. The current public and private expenditure on health (as a percentage of GDP) are meager, i.e., $0.8 \%$ and $2.6 \%$ respectively [3]. There are numerous such examples.

\subsection{Project location}

Katsina is the $5^{\text {th }}$ most populous and $17^{\text {th }}$ largest province of Nigeria and is located at about $500 \mathrm{KM}$ from Abuja, the national capital. It has a population of 5,792,578 (51.0\% males, <15 years: $49.0 \%,>65$ years: $3.0 \%$, life expectancy: 55.2 years according to 2016 census) [14-17]. Most of them belong to Hausa, the largest ethnic group of Africa, with contemporary Islam as their predominant religion. Katsina currently has a total of 34 Local Government Areas (LGAs), the $2^{\text {nd }}$ most of all in Nigeria.

\subsection{Procedures}

For this work, we prepared a comprehensive list of all active service-delivery facilities that are catering to an ongoing public health program (both national and provincial) on malaria (national), family planning (national), routine immunization (national), HIV/AIDS (national), tuberculosis and leprosy (national), and Free Medicare-women and child (provincial). A simple random sample of facilities was after that derived from this source population by assuming that $50.0 \%$ facilities would have a "gold-standard situation" on five chosen key performance indicators as shown in Table 2, 95\% Confidence Interval (CI), $3.5 \%$ variance between groups, and $10.0 \%$ total width of CI [18]. 
Table 1. Sample size determination from number of service points of programs to be visited

\begin{tabular}{cccc}
\hline S/N & Program Area & $\begin{array}{c}\text { Number of Health Facilities Where } \\
\text { Services Are Provided }\end{array}$ & $\begin{array}{c}\text { Sample } \\
\text { Size }\end{array}$ \\
\hline 1 & *HIV/AIDS & 19 & 19 \\
2 & Malaria & 1.718 & 315 \\
3 & Tuberculosis \& Leprosy Control & $173 *$ DOTS centres & 120 \\
4 & Routine Immunization (RI) & 1.623 & 311 \\
5 & Family Planning & 393 & 195 \\
6 & Free Medicare & 25 & 24 \\
\hline *DOTS: & Directly Observed Treatment & Short Course; *HIV/AIDS: Human Immunodeficiency \\
\multicolumn{2}{l}{ Virus/Acquired Immune Deficiency Syndrome; S/N: Serial Number }
\end{tabular}

In order to collect required data, we used a validated questionnaire, named the Logistics Indicator Assessment Tool (LIAT) that covered various aspects related to indicators of our interest [19]. These included: (a) accuracy of inventory data, (b) demand versus receipt of required health products, (c) actual storage conditions in-place, (d) near-term availability of required medications, (e) frequency of stock-out of health products. All these indicators were examined in details. For instance, for the accuracy of inventory data, the physical balance of the products and most recent requisition reports were matched.

Similarly, demand versus receipt was examined by referring to the quantities ordered as per requisition reports and quantity received as per supplier's proof of delivery. The actual storage conditions were examined by using a set of 17 sub-indicators (e.g., the arrangement of products with labels visible, physical conditions of cartons and packs, a quarantine area for unusable stock, etc.). Near-term product availability was examined by taking stock at-hand vis-à-vis average monthly consumption of the facility to see if the stock would last till the next due supply. A stock-out was measured as a point estimate, i.e., on the day of the examination, and in the preceding six months, along with the duration of stock-out that may have happened. All facilities use an identical number and nature of health products for their part of activities. For this work, all eleven (11) field staff recruited received three rounds of training on orientation, practical filling of LIAT, and mock data collection. All data were systematically entered in MS-Excel and appropriately analyzed. Ethics permission was obtained from the Institutional Review Board of Pôle Universitaire Euclide. Informed consent was obtained from all participants before their participation. No direct patient-related or any other identification data was collected.

\section{RESULTS AND DISCUSSION}

A total of 1,718 facilities were found to be operational in our province. Of them, a total of 983 (57.22\% of the total) facilities were surveyed across all LGAs in the province. These belonged to HIV/AIDS $(\mathrm{n}=15,78.9 \%)$, Free Medicare-women and children $(\mathrm{n}=15,60.0 \%)$, tuberculosis and leprosy $(\mathrm{n}=123,71.1 \%)$, family planning $(\mathrm{n}=195,49.6 \%)$, malaria $(\mathrm{n}=319,18.6 \%)$, and routine immunization $(n=311,19.5 \%)$. For convenience, the remaining results are summarized in Tables 3 and Table 4.

Table 3. Collated data for logistics indicators assessment of six public health programs in Katsina State, Nigeria

\begin{tabular}{ccccccc}
\hline Parameter & $\begin{array}{c}\text { Malaria } \\
(\mathrm{n}=319)\end{array}$ & $\begin{array}{c}\text { RI } \\
(\mathrm{n}=316)\end{array}$ & $\begin{array}{c}\text { FP } \\
(\mathrm{n}=125)\end{array}$ & $\begin{array}{c}\text { TBL } \\
(\mathrm{n}=123)\end{array}$ & $\begin{array}{c}\text { HIV } \\
(\mathrm{n}=15)\end{array}$ & $\begin{array}{c}\text { FMC } \\
(\mathrm{n}=15)\end{array}$ \\
\hline Mean staff experience (in months) & 181 & 182 & 90 & 77 & 47 & 47 \\
Presence of road & 253 & 215 & 159 & 108 & 15 & 15 \\
Presence of electricity & 82 & 74 & 65 & 64 & 15 & 15 \\
Presence of water supply & 69 & 74 & 63 & 73 & 15 & 15 \\
No. of products used & 12 & 17 & 9 & 18 & 23 & 165 \\
Emergency orders placed & 50 & 40 & 39 & 16 & 7 & 0 \\
Determine quantities themselves & 114 & 275 & 118 & 44 & 5 & 0 \\
6-month stock-out & 201 & 0 & 99 & 23 & 5 & 15 \\
Point frequency of stock-out & 184 & 0 & 75 & 34 & 5 & 15 \\
No. of days stocked out & 222 & 0 & 135 & 1 & 4 & 30 \\
Keep records of expired products & 66 & 37 & 6 & 11 & 1 & 0 \\
\hline
\end{tabular}


Table 4. Rated performance $(\%)$ of the core logistics indicator

\begin{tabular}{|c|c|c|c|c|c|c|}
\hline Core Logistics Indicator & Malaria & RI & FP & TB & HIV & FMS \\
\hline Indicator 1: Accuracy of logistics data for inventory management & $98 \%$ & $99 \%$ & $91 \%$ & $96 \%$ & $97 \%$ & $100 \%$ \\
\hline $\begin{array}{l}\text { Indicator 2: Percentage difference between the quantity of products } \\
\text { ordered and the quantity of products received } * \text { (the lesser, the better) }\end{array}$ & $100 \%$ & $1 \%$ & $8 \%$ & $2 \%$ & $2 \%$ & $100 \%$ \\
\hline $\begin{array}{l}\text { Indicator 4: Percentage of facilities whose stock levels ensure near- } \\
\text { term product availability }\end{array}$ & $83 \%$ & $100 \%$ & $100 \%$ & $83 \%$ & $96 \%$ & $92 \%$ \\
\hline
\end{tabular}

Logistics systems in Nigeria are facing many challenges. The biggest is funding which is somewhat unilateral- mostly donors' fund used to support the entire system [20]. Counterpart funding has been wholly ineffective. Consequently, stock-outs loom for many products. Another significant challenge faced by logistics systems is the storage conditions of health commodities. Nearly all medical stores are not of pharmaceutical grade. Thirdly, data quality has challenges ranging from updating records, missing reports, errors in reporting, and quality of data often is inadequate [21]. Logistics technical know-how is also highly inadequate among service providers in health facilities.

The challenges of logistics systems in Nigeria are more pronounced in the Northern part of the country where literacy level and coverage are low [22]. The indices of health and logistics of health commodities in Katsina State are very poor particularly in the direction of maternal \& child health and nutrition [23]. Of the five disease areas identified and supported by the Nigeria Supply Chain Integration Project (NSCIP), there is no information on the performance of at least the five core logistics indicators [24].

We performed a very comprehensive examination of six ongoing public health programs in Katsina State, for which we used five key performance indicators. This work was necessary for several reasons but, as far as we are aware, this is the first work from Africa that has formally utilized a validated instrument and five formal indicators for a program-based evaluation. Earlier efforts have only been restricted to using a single indicator, or just being an informal internal evaluation. Our work has, therefore, succeeded to fill knowledge-gaps to some extent.

A total of 1,718 facilities were found to be operational in our province, which implies that (assuming a normal distribution) each facility is expected to cover only about 3,371 individuals. This is a critical system-related "opportunity" that may help in providing a structured decentralized program-based objective-driven health care services for possible sustained performance and patient benefits [25]. In total, we surveyed $57.22 \%$ of the existing facilities. Thus, our work is reasonably representative of public health activities that are taking place, either as a national or a provincial program. For instance, we surveyed $78.9 \%$ and $71.1 \%$ of all facilities where HIV and tuberculosis and leprosy respectively services are provided.

The choice of our province was also appropriate. For instance, Hausa, the predominant ethnic group of Katsina, is $29.0 \%$ of the total Nigerian population. Both Katsina and the Nigerian population are similarly young $(49.0 \%$ and $43.0 \%$ respectively are $<15$ years of age). Islam is the predominant religion of Katsina, and about $50.0 \%$ of Nigerians practice it. There can be numerous such examples. Thus, our results may be considered to fairly reflect current public health program-based healthcare delivery situation that is being carried out in a Nigerian cultural context, as a whole.

For any program evaluation and optimal performance, data accuracy is an essential parameter. None of our programs had a data deficiency, although numeric differences were found between programs. These differences might be due to various factors, such as differences in the "individual capacity" (e.g. quality and length of staff experience) and "compensation" (e.g. better dedication towards work), or "operational convenience factors" (e.g. distance to home, training facilities), or "donor-related factors" (e.g. funding input for better infrastructure), or "political factors" (e.g. centralized or decentralized drug supply), etc [26-30]. Elsewhere, data quality issues have been reasonably noted which may be due to incessant stock-outs, poor donor engagement, inadequate capacity building of personnel, complexity in supply procedures, etc [31-33]. Here, absence of difference in data discrepancy between programs could probably be methodological (e.g., inadequate sample size for detecting such a difference). This may also be probably because all of our facilities undergo the same kind of staff training and uses the same kind (and number) of health products for implementing their part of public health programs. Moreover, our field staff was systematically trained for two days, and each indicator was reasonably defined and comprehensively evaluated. This may have caused some difference than elsewhere, but this can only be speculated.

The disparity between the quantity of products ordered and those received is a core logistics indicator. In the LIAT, this indicator is tracked going by the name, a discrepancy that implies that the lesser 
the values obtained, the better the performance. Due to the practice of the push system, both malaria and Free Medicare programs recorded $100 \%$ discrepancy indicating that whatever quantities the facilities requested were not the issued amounts to them. For the malaria program, the main reason was due to program expansion without corresponding quantification and increased funding while for the Free Medicare, it is purely due to insufficient financing which could not afford to buy commodities to satisfy $100 \%$ of client burden.

The FP program recorded $8 \%$ discrepancies between what they ordered and what they were issued. HIV/AIDS, tuberculosis, and routine immunization reported 2\%, 2\%, and 1\% discrepancies. On average, the state has $36 \%$ discrepancies, but this was caused principally by malaria and Free Medicare programs that operate on a push system of issuing commodities to health facilities. Storage conditions form a core indicator and are a range of best practices that should be in place to store health commodities. Proper storage conditions are undoubtedly required to preserve the potency and efficacy of all products intended for use as medicines, diagnostics, or consumables.

There are many critical things to look at to conclude that storage conditions have been met. In this study, up to 17 other indicators have been evaluated to assess this particular indicator. Having adopted an $85 \%$ recommended pass score for the core indicator; it is evident that all the public health programs assessed have passed the assessment. The least scores were $85 \%$ scored each by malaria and routine immunization programs. Tuberculosis \& leprosy, family planning, HIV/AIDS, and Free Medicare are performing optimally at 91\%, 93\%, 96\%, and 96\% respectively. Overall the state has an average of $91 \%$ pass for this indicator, and it appears that it is working across the entire state.

Stock status is a core logistics indicator. All public health programs assessed operate within a maximum and minimum inventory control window. This indicator is the flipside of the stock out indicator. The percentage pass for stock out having been fixed at not exceeding 20\%, a stock status of not less than $80 \%$ is expected to be maintained for a program is considered as passing the indicator. The study found that at the time of the assessment, there were high stock levels across all programs. Malaria and tuberculosis \& leprosy programs had recorded $83 \%$ each, Free Medicare program had $92 \%$ stock availability, HIV/AIDS program maintained stock levels at $96 \%$, and both routine immunization and family planning programs maintained $100 \%$ stock availability. Overall, public health programs had an average stock availability of $92 \%$.

This indicator is the flipside of stock out rate. In order words, if a stock level of $80 \%$ is desired, then stock out rate should not exceed $20 \%$.The level of stock availability, the patient load of the different logistics system can be a measure of how much commodity security is available for each disease program. The routine immunization program had $100 \%$ commodity security for 330,353 children that are below the age of one year and need to be immunized in the state.

The family planning program has the second highest patient load with a total of 140,147 clients aged between 15-49 years that are using modern contraceptives in 2018. The FP program also had a record of $100 \%$ commodity security for over 140,000 clients accessing services. The next program in terms of the high patient load is the Free Medicare program with a record of 65,670 patients in April-June 2018 only. As at the time of this assessment, the Free Medicare had 92\% availability of commodities. With stock availability of $95 \%$, the HIV/AIDS program has 9,435 clients on treatment across 19 health facilities. Tuberculosis \& leprosy program has 889 adult cases and 524 children cases on treatment, which represent a total of 1,413 clients' burden for the program and had $83 \%$ stock availability for all the clients. Lastly, the malaria program has the most significant number of facilities supported, but unfortunately, there is no established number of people on treatment because malaria is treated per episode of attack.

Of all indicators we evaluated, the most obvious challenge was in the stock-out, and therefore, in demand $v s$. receipt, of health products as shown in Table 3. This stock-out was visible for all programs except routine immunization and tuberculosis and leprosy. This might be interpreted in numerous ways. Firstly, nearly all of the facilities in these two programs were estimating their requirement themselves as shown in Table 3 which may have helped in part through better assessment of local scenarios. These two programs had a relatively low number of stock-out days as well as shown in Table 3. Secondly, the stock-out might be in part related to the number of health products being used in a program as shown in Table 3 . For instance, Free Medicare uses 165 products, and $62.0 \%$ of its facilities were out of stock for six months as shown in Table 3. Thirdly, stock-out in Africa should not be unexpected because more than $90.0 \%$ of health products in Africa are imported from outside [34-40]. This, therefore, is subjected to external factors as well as in-country regulations and restrictions. To elaborate further, Nigeria has about 130 pharmaceutical companies, but only $8.0 \%$ of them have a sustainable operation. A formal evaluation of them has shown poor performance, for instance, capacity utilization of just about $40.0 \%$ [41]. Having no local availability of active ingredients is another significant hindrance towards a desirable level of availability and access to essential medications. No doubt, the pharmaceutical sector here accounts for merely $0.2 \%$ of Nigeria's GDP [42].

Performance assessment of six public health programs in Katsina State, Nigeria (Laurent Cleenewerck) 
While comparing point (on the day of observation) and six-monthly stock-out, Table 3, there was not much subsequent decline in the stock-out. For instance, in malaria and family planning, the stock-out was for 222 and 135 days, respectively, Table 3. Thus, poor pharmaceutical scenario (e.g., stagnant supply, over-reliance on external stakeholders, in-country challenges) is a significant feature of the healthcare delivery system here in Nigeria. This again should not be unexpected since elsewhere it is shown that donor-funded programs do not lead to simultaneous broad "horizontal" development of local healthcare delivery system [42]. For instance, a centralized procurement does not always mean a timely transport of supplies to provinces. Fourthly, another reason of stock-out might be an abrupt change in caseload as it may be seen in emergency orders placed by the programs, Table 3, such as malaria. This should not be unexpected in population like ours where caseload may change by $52.0 \%$ over a relatively short period [3]. Moreover, in Nigeria, disease conditions such as malaria are generally treated per episode of attack and not by its total number of caseload.

Lastly, as far as we are aware, ours was the first comprehensive attempt to evaluate, and in turn identify challenges for, the delivery of public health programs in Africa. Our work visibly has its application across various interest areas including health policy making, critical decision and risk analysis, access and delivery of quality healthcare, health system evaluation, and is likely to strengthen our knowledge from a systems perspective; wherein everything is likely to be affected by everything else. Nevertheless, our work does not include those programs that are periodic or time-bound. Our work was not designed to identify predictors that may have affected performance between different programs and facilities. For instance, the military rule is common in Nigeria (until 1999 when democracy came to stay) that may affect the performance, benefit, and continuity of programs.

\section{CONCLUSION}

Positively, six sizeable public health programs were overall found to meet most of the key performance indicators in a systematic evaluation of 983 health facilities. Negatively, most programs (except routine immunization and tuberculosis \& leprosy) fail in the parameter of stock-out of required health products. Our work also implies that program-based healthcare is of little long-term benefit for installing a "broad" improvement in the healthcare delivery system in the host country. Our work also implies that public health programs in Nigeria quite likely to follow a "push" system to meet their essential supplies. Lastly, our work calls policymakers to adopt a self-help model through strengthening the local pharmaceutical sector in order to bring better patient benefits and meet relevant public health and development goals.

\section{ACKNOWLEDGMENTS}

It is with profound gratitude that the authors wish to acknowledge the ethics permission of the Institutional Review Board of Pôle Universitaire Euclide. The authors also want to appreciate the efforts of the 11 data collectors and 983 logistics officers at health facilities that gave the consent for interview and assessment of health facility records.

\section{REFERENCES}

[1] Luis, S. "African Regional Health Report 2006," last modified 2006, accessed January 24, 2019, https://www.afro.who.int/sites/default/files/2017-06/african_regional_health_report2006_0.pdf.

[2] Gretchen, B. "The Social and Economic Impact of Epilepsy in Zambia: A Cross-Sectional Study." Lancet Neurology. Last modified January 2007, accessed January 24, 2019, https://www.ncbi.nlm.nih.gov/pmc/articles/PMC2938018/.

[3] Faisal, M., Jamil, A., Alauddin, C. "Major Public Health Problems in Nigeria: A Review | South East Asia Journal of Public Health," last modified 2017, accessed January 25, 2019, https://www.banglajol.info/index.php/SEAJPH/article/view/34672.

[4] Gulma, Kabiru A. Handing Over of Logistics and Supply Chain Activities of MNCH2 Program. Katsina, September 2018.

[5] DfID/MNCH2. "Mapping of Supply Chain Systems in Katsina State, Nigeria," February 1, 2018.

[6] Nasiru, Yusuf (ed.). Katsina State Quarterly Stock Status Journal (April - June 2017). Katsina, July 2017.

[7] Shittu, Abdulkadir (ed.). Katsina State Quarterly Stock Status Journal (April - June 2018). Katsina, July 2018.

[8] Ibrahim, Jabir B. (ed.). Katsina State Quarterly Stock Status Journal (January - March 2018). Katsina, April 2018.

[9] Yahaya, Mukhtar (ed.). Katsina State Quarterly Stock Status Journal (July - September 2017). Katsina, October 2017.

[10] Comlavi, Danny P. Katsina State Quarterly Stock Status Journal (October - December 2017). Katsina, January 2018.

Int. J. Public Health Sci. Vol. 8, No. 1, March 2019: 127 - 134 
[11] Richard, Idro. "Cerebral Malaria; Mechanisms of Brain Injury and Strategies for Improved Neuro-Cognitive Outcome." Pediatric Research. Accessed January 2019, https://www.ncbi.nlm.nih.gov/pmc/articles/PMC3056312/.

[12] “Leprosy (Hansen's Disease) - Better Health Channel," last modified 2017, accessed January 25, 2019, https://www.betterhealth.vic.gov.au/health/conditionsandtreatments/leprosy.

[13] Devender B. "Population-Based Study of Epilepsy in Cambodia Associated Factors, Measures of Impact, Stigma, Quality of Life, Knowledge-Attitude-Practice, and Treatment Gap.” PLOS ONE. Accessed January 25, 2019, https://journals.plos.org/plosone/article?id=10.1371/journal.pone.0046296.

[14] Ibrahim Shuaibu. "Katsina State Celebrates 30 Years of Statehood." THISDAYLIVE, October 3, 2017. Accessed October 5, 2018. https://www.thisdaylive.com/index.php/2017/10/03/katsina-state-celebrates-30-years-ofstatehood/.

[15] Latitude.to. "GPS Coordinates of Katsina, Nigeria. Latitude: 12.9908 Longitude: 7.6018." Latitude.to, Maps, Geolocated Articles, Latitude Longitude Coordinate Conversion. Last modified 2018. Accessed October 5, 2018. http://latitude.to:8080/map/ng/nigeria/cities/katsina.

[16] "Katsina State Land Area." Accessed 2018. https://www.google.com.ng/search?rlz=1C1HLDY_enNG705NG705\&q=katsina+state+area\&stick=H4sIAAAAA AAAAONgFuLUz9U3MKvIyi1RQjC1Jzzc3Pz84IzU1LLEyuLFzFKZSdb6efkJyeWZObnwRIWiUWpiQDJmJXyRQAAAA\&sa=X\&ved=2ahUKEwjD_4 Whiu_dAhVKKcAKHY-jC-kQMSgAMAN6BAgGEAs\&biw=1366\&bih=626.

[17] "2006 PHC Priority Tables - NATIONAL POPULATION COMMISSION," n.d. Accessed July 8, 2018. http://population.gov.ng/core-activities/surveys/dataset/2006-phc-priority-tables/.

[18] Hulley SB, Cummings SR, Browner WS, Grady D, Newman TB. Designing Clinical Research: An Epidemiologic Approach. 4th ed. Philadelphia, PA: Lippincott Williams \& Wilkins; 2013. Appendix 6E, page 81.

[19] John Snow, "Logistics Indicators Assessment Tool (LIAT)" (2008): 44.

[20] Aregbeshola, B., "Health Care in Nigeria: Challenges and Recommendations," last modified April 11, 2018, accessed December 28, 2018, http://socialprotection.org/learn/blog/health-care-nigeria-challenges-andrecommendations.

[21] Chioma, O. "Tackling Menace of Poor Data Collection in Nigeria's Health Sector," last modified December 17, 2015, accessed December 28, 2018, https://www.vanguardngr.com/2015/12/tackling-menace-of-poor-datacollection-in-nigerias-health-sector/.

[22] George, I., "What are the Problems Facing Healthcare Management in Nigeria? $\triangleright$ Legit.Ng," last modified May 26, 2017, accessed December 28, 2018, https://www.legit.ng/1104912-what-the-problems-facing-healthcaremanagement-nigeria.html.

[23] MNCH2. "Katsina State." MNCH2 Nigeria, n.d. Accessed October 13, 2018. http://www.mnch2.com/katsina-state/.

[24] "What Are Indicators and Types of Indicators? | Monitoring and Evaluation Studies," accessed October 2, 2018, http://www.mnestudies.com/monitoring/what-indicators-and-types-indicators.

[25] MaRi Eagar, "What Is the Difference between Decentralized and Distributed Systems?," last modified 2017, accessed January 25, 2019, https://medium.com/distributed-economy/what-is-the-difference-betweendecentralized-and-distributed-systems-f4190a5c6462.

[26] Kingma, M. Workplace Violence in the Health Sector: A Problem of Epidemic Proportion. International Nursing Review, 2001: 48(3), 129-130.

[27] Westin, T., Stalfors, J. Tumor Boards/Multidisciplinary Head and Neck Cancer Meetings: Are they of Value to Patients, Treating Staff or a Political Additional Drain on Healthcare Resources? Current Opinion in Otolaryngology \& Head and Neck Surgery: April 2008 - Volume 16 - Issue 2 - p 103-107.

[28] Jeremy, S. Donor Funding Priorities for Communicable Disease Control in the Developing World. The Journal on Health Policy and Systems Research, Volume 21, Issue 6, 1 November 2006, Pages 411-420.

[29] Karen, A. G., Crossley, B. P., Zubin, C. S., Abdul, G. Donor Funding Health Policy and Systems Research in Lowand Middle-Income Countries: How Much, From Where and to Whom. Health Research Policy and Systems, 2017, 15:68.

[30] Pitt C, Grollman C, Martínez-Álvarez M, et al. Countdown to 2015: An Analysis of Donor Funding for Prenatal and Neonatal Health, 2003-2013. British Medical Journal Global Health, 2017; 2: e000205.

[31] Louis, N., Solomon, M., Cheryl, L. A., Jackline, O., Elisephan, N., Laura, C., Joseph, M., Bethany, H. Assessment of Essential Medicines Stock-Outs at Health Centers in Burera District in Northern Rwanda. Rwanda Journal Series F: Medicine and Health Sciences. Vol. 2 No. 1, 2015.

[32] Carl-Andy, D., Debbie, S. From Staff-Mix to Skill-Mix and Beyond: Towards a Systemic Approach to Health Workforce Management. Human Resource Health. 2009; 7: 87.

[33] Y. Xiao et al., "Challenges in Data Quality: The Influence of Data Quality Assessments on Data Availability and Completeness in a Voluntary Medical Male Circumcision Programme in Zimbabwe," British Medical Journal Open 7, no. 1 (January 1, 2017): e013562, accessed January 30, 2019, https://bmjopen.bmj.com/content/7/1/e013562.

[34] Ngai-Hang Z. L., Ana, C., Prashant, Y., Jérémie, G. The Impact of Inventory Management on Stock-Outs of Essential Drugs in Sub-Saharan Africa: Secondary Analysis of a Field Experiment in Zambia. PLOS ONE, May 2016.

[35] Phares, G. M. M., Maureen, M., Mary, J., Marc, W. Local Production of Pharmaceuticals in Africa and Access to Essential Medicines: 'Urban Bias' in Access to Imported Medicines in Tanzania and its Policy Implications. Global Health, 2014; 10: 12. 
[36] Bateman. Drug Stock-Outs: Inept Supply-Chain Management and Corruption. South African Medical Journal, Vol 103, No 9, (2013).

[37] Margareth, N., Jacqueline, M., Shan, N., Alexander, D., Eliangiringa, K. Medicines Regulation in Africa: Current State and Opportunities. Pharmaceutical Medical Journal. 2017; 31(6): 383-397.

[38] Swathi, I., Lisa, H., Gilles, F., Suzanne, H. Medicine Shortages: A Commentary on Causes and Mitigation Strategies. BMC Medical Journal, 2016; 14: 124.

[39] Maria, J. Access to Drugs at Risk: Securing Access to Medicines for Least Developed Countries. Africa Development Journal, Volume XLII, No. 1, 2017, pp. 101-120.

[40] Atholl, J., David, W. H. Substandard Drugs: A Potential Crisis for Public Health. British Journal of Clinical Pharmacology, 2014 Aug; 78(2): 218-243.

[41] Ogechukwu, C. U. "A Strategic Study of the Nigerian Pharmaceutical Sector: Organizational Leadership, MarketShare, and Competitive Performance." International Journal of Business, Humanities, and Technology. 7, No. 1 (2017): 10.

[42] Basile, K. "The Interface between Health Systems and Vertical Programmes in Francophone Africa: The Managers' Perceptions: Programmes and General Health Services Interface.” Tropical Medicine \& International Health. Vol. 16, no. 4 (April 2011): 478-485, accessed January 25, 2019, http://doi.wiley.com/10.1111/j.13653156.2010.02716.x.

\section{BIOGRAPHIES OF AUTHORS}

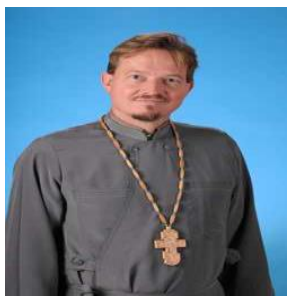

\section{Pr. Laurent Cleenewerck, STL, MES, DSc, FRSPH}

Laurent Cleenewerck is a professor of international administration and theology at Euclid University with interest and expertise in interfaith studies and bioethical issues. He was educated in France at the University of Montpellier and Institut Saint Serge of Paris. He pursued graduate studies at St Tikhon's Orthodox Theological Seminary (United States) and obtained a master's degree in ecumenical studies from the Ukrainian Catholic University. His doctoral dissertation on the interface of physics and theology was presented at the St Gregory Nazienzen Institute (now part of Nikola Tesla Union University). He also completed a master's in international public health on the faculty track as well as a number of specialized certificates in global health and bioethics. His academic interests focus on the intersection of science, interfaith studies and bioethics.

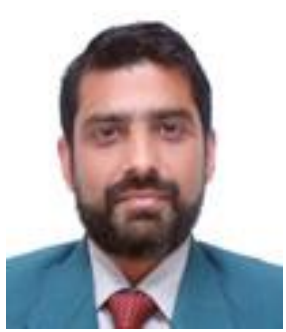

\section{Devender BHALLA, Ph.D. HDR}

Devender Bhalla is a professor of international public health at Euclid University. A physician by training with a number of international awards to his credit. Devender is a Schoenberg awardee of the American Academy of Neurology and also a fellow of the Royal Society of Tropical Medicine and Hygiene. He is also a member of the Faculty of Public Health, Royal College of Physicians, United Kingdom and Sudan League of epilepsy and Neurology (SLeN). Devender is a medical reviewer of Research Council, Mauritius and also editorial board member of the Journal of Neurology and Geriatrics.

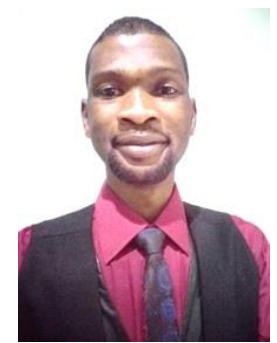

Kabiru Abubakar Gulma, B. Pharm, MBA, Ph.D.

Kabiru Abubakar Gulma is a public health specialist with interest in supply chain management of health commodities. He obtained his first degree (Bachelor of Pharmacy) from Ahmadu Bello University, Zaria, Nigeria and a Master of Business Administration (MBA) with specialization in supply chain and project management from Assam Don Bosco University, India. Recently, Kabiru graduated from Euclid University with a Doctor of Philosophy (Ph.D.) in International Public Health. Kabiru is an author with three published books to his credit, some peer-reviewed publications in international journals, and is also a reviewer. 